\title{
OSTEOARTHRITIS AND IMMUNITY
}

\author{
I. Momcheva1, I. Kazmin', Sv. Hristova², V. Madgova² \\ ${ }^{1}$ Department of Rheumatology, UMHAT - Burgas \\ ${ }^{2}$ Department of General Medicine and Clinical Laboratory, MU - Varna
}

\begin{abstract}
Low-grade inflammation is part of the pathogenesis of osteoarthritis (OA) from its earliest stages and contributes to the acceleration of the degenerative process. Innate immunity has a leading role in it. Activation of the innate immune response is initiated by stimulation of the receptors on the cell membrane to recognize the secreted PAMPs (pathogen-associated molecular patterns). However, PAMPs can also be activated by endogenous damage-related molecular patterns (DAMPs). The group of DAMPs also includes toll-like receptors (TLRs). The disruption of matrix homeostasis in the course of OA is an example of activation of these receptors in chronic damage. The complement system is a key element of the innate immune system. It is one of the serum enzyme systems whose function is to opsonize antigens. The complement receptors on the surface of the cell membranes adhere to the targets for phagocytosis. The C3R fraction activates the complement cascade itself, as well as the oxygen metabolism of the cell, which is essential for the phagocytosis. The cartilage damage products released during joint damage are a separate class of potent complement modulators. Complement fractions bind to complement receptors on the surface of the chondrocyte and the synoviocyte cell membranes by TLR. The complement system is involved in many processes in the course of osteoarthritis: chondrocyte degeneration, ECM degradation, low-grade inflammation in the osteoarthritis, cell lysis, unbalanced bone remodeling, osteophyte formation, and neoangiogenesis. Whether drug control of complement activation may be a future therapeutic strategy in the treatment of $O A$ and prevent its progression is a subject of future studies.
\end{abstract}

Key words: osteoarthritis, immunity, receptors, complement system, phagocytosis

Low-grade inflammation is part of the pathogenesis of osteoarthritis (OA) from its earliest stages and contributes to the acceleration of the degenerative process. Innate immunity has a leading role in it. This fact is supported by multiple studies [1]. It is not connected to the expressed adaptive immune response.

Circulating macrophages, together with the other phagocytizing cells (polynuclei, Mo, Eo, OK, Ma in the spleen, lymph nodes, skin; Kupffer cells in the liver; mesangial phagocytes; microglial cells in the central nervous system, type-A synoviocytes in the synovium, histiocytes in the connective tissue) are the main cellular representatives of non-specific immunity. NK cells (neither B nor T, destroying viral-invaded or tumour-changed cells) as well as physical barriers (skin and mucous membranes) [2] also participate. Here is the place to note the role of dendritic cells as immune system coordinators as well. They are macrophages specialized as antigen-presenting cells and are a separate branch of myeloid order. They migrate from the bone marrow into different organs and tissues (usually contacting with the external environment) and they play the role of an immunological sensor. Being present in most tissues, expressing TLR on their cell membrane, they active or suppress T-cells and are an important link between innate and adaptive immunity [3].

Activation of the innate immune response is initiated by stimulation of the receptors on the cell membrane to recognize the secreted pathogen-associated molecules - classical microbial ligands. These receptors are called PAMPs - pathogen-associated molecular patterns. Apart from the cases of infection, those receptors are recognized and activated with damaged cells and extracellular matrix [4]. In the conditions of degenerative joint changes, ECM components, fibronectin isoforms, fragments of hyaluronic acid are supposed ligands for PAMPs. In these cases, PAMPs can also be activated by endogenous damage-related molecular patterns (DAMPs), and not by microbial ligands. The group of DAMPs also includes toll-like receptors (TLRs), constructively expressed on the cell membrane of different cells, including macrophages - through TLR-4 [5, 6]. A number of the PAMPs-receptors of mammals are members of the TLRs family. A human-being has at least 10 TLRs. Different ligands active different TLRs. The disruption of matrix homeostasis in the course of $\mathrm{OA}$ is an example of activation of these recep- 
tors in cases of chronic damage. TLRs 1-7 and 9 are found in the synovium in cases of OA and PA, and in cases of in-vitro studies synovial fibroblasts react to their activation $[7,8,9,10]$. The cellular response which follows is through activating specific transcription factors, among which nuclear-factor KB (NF-kB) plays the main role. TLR activation in SM is a stimulus for an NFKB activation, followed by production of chemokines (IL-8 and CCL5) and cytokines (IL-1, IL-6 and TNF), with association and activation of Ma, granulocytes, and lymphocytes [11]. Chondrocytes can also serve as targets for TLR-activation. A number of matrix metalloproteinases, produced by the cartilage in cases of $\mathrm{OA}$, depend on the activation of NF-KB $[12,13]$. Despite the incompletely clarified role of TLRs in cases of OA, their targeting, as well as the ways of their activation are to be analyzed as potential therapeutic approaches in cases of OA.

The humoral components of innate immunity are the CRP and the complement system.

The complement system is a key element of innate immune system $[14,15]$. It is one of the serum enzyme systems whose function is to opsonize antigens. This means easier antigen-immunocyte and antigen-antigen relations; preparation of the antigen for phagocytosis, increased membrane permeability, and mediation of the inflammation. In the past decade, the complement system has been reviewed as a bridge between innate and acquired immunity. It consists of more than 50 proteins and glycoproteins, including serum proteins and cell-membrane receptors, which are basically synthesized by hepatocytes [16] and in less amounts by tissue macrophages, by blood monocytes, by epithelial cells of gastrointestinal and urogenital tract, and by type-A synoviocytes. They represent around $5 \%$ of the globulin fraction of blood serum and circulate in blood as inactive precursors. Class-III HLA-gene molecules code some of the complement components: $\mathrm{C} 2, \mathrm{C} 4$, and C3 proactivators [3]. When an exogenic or an endogenic trigger activates the complement system, proteases cut complement proteins, activate them, and actuate the system's cascade. Activation is a chain reaction based on proteolysis, as system activity increases on each step of the cascade. The three ways of complement activation (classical, alternative, and lectin) have a common key stage of activation - C3-convertase protease. It cuts and actives the $\mathrm{C} 3$ component, creating $\mathrm{C} 3 \mathrm{a}$ and $\mathrm{C} 3 \mathrm{~b}$ $[17,18]$. The products from C3 decomposition may serve for assessing complement system activation. In difference to the specified C3 fragments, C3c does not connect to other structures like pathogens, cellular receptors or plasma proteins, which is why it is a reliably stable biomarker for assessing C3 activation. C3-conversion in C3c is done for around an hour, under body temperature and, in difference to other C3-fractions, which are with a short semilife, it is stable and used for assessment of the C3 levels in laboratory tests $[19,20]$. The surface of many cells has complement receptors - CR. Their function is to adhere objects targeted for phagocytosis. The C3R fraction activates the complement cascade itself, as well as the oxygen metabolism of the cell, which is essential for the phagocytosis. Defects in C and CR (genetically determined) lead to a defect in phagocytosis, respectively, infections, autoimmunity, etc. [3].

C4 participates in the classical (properdin) way of complement activation (it is activated by specific antibodies in difference to the alternative one, which is activated without the presence of such). If, in case of inflammation, C4 is at a normal level, the probable way of activation is the alternative one. C4 is reduced in case of activated С thyroiditis, bacterial or viral meningitis, streptococcus and staphylococcal sepsis, etc. It is increased in cases of chronic inflammation conditions, pregnancy, etc. [21, 22]. There are activation triggers for each way of complement cascade [23, 24].

The alternative way does not have a specific activation and is a major C3 component; the classical one is activated by a specific antibody and $\mathrm{C} 4$ is a main participant in it; while the lectin way is activated through carbohydrate recognition on the microbial surface (mannose-binding lectin - MBL and mannose-binding protein - MBP) [25, 26]. Complement activation is based on proteolysis and generation of small soluble fragments. The most common methods of quantitative specification of C3 and C4 measure intact proteins, as well as the major soluble fragments formed with activation [27]. The last unit of complement cascade activation is binding C5b with $\mathrm{C} 6$ and $\mathrm{C} 7$ in a membrane attack complex (MAC). MAC is a cytolytic end-product of the complement cascade, which, through $\mathrm{C} 5 \mathrm{~b}$, adheres to the cell membrane and forms a transmembrane channel, which leads to an osmotic lysis to the target cell. Membrane lysis is accelerated by C9 (perforin) and a membrane channel, through which calcium ions, $\mathrm{NaCl}$ and water $[3,17,18]$ penetrate, is formed. The final result of complement activation is lysis of target cells, opsonization, followed by chemotaxis of macrophagues, and transportation of immune 
complexes to the Kupffer cells in the liver and to the spleen, in order to purify them [28, 29].

The complement system, as a part of innate immunity, is one of the first lines of protection against external pathogens. Apart from this major, evolutionary determined protective function, it also plays a role in the removal of cellular remains and immune complexes, opsonization, and B- and T-lymphocyte stimulation [30]. The cartilage damage products released during joint damage are a separate class of potent complement modulators [31, 32, 33, 34]. Different ECM components and their fragments in the degenerative joints can also active the complement [35, 36]. Fibromodulin [37], cartilage oligomeric matrix protein (COMP) [38] and osteoadherin [39] can activate complement cascade, both in the classical and in the alternative way. Complement activation in the joint can also be directly activated by a mechanical stress and with a local production of complement factors of type-A synoviocytes at the activation of arthrosis. The data from analyses of joint traumas in the first several weeks after the trauma supports this thesis. [40, 41]. Other matrix components, such as NC4 domain of type-IX collagen, act like complement inhibitors $[42,43)$. Lots of data from the last studies supports the thesis that low-grade inflammation in cases of OA includes TLR involvement and complement cascade activation, through the degradation products of joint destruction [44, 45, $46,47]$. The inflammatory synovial reaction which follows leads to a synthesis and release of a variety of cytokines and chemokines [48, 49]. Humoral factors of inflammation are a potent hepatostimulating factor for a CRP synthesis and other acute-phase proteins. CRP in the serum and undergoes calcium-dependent binding with protein molecules like phosphorylcholine, nuclear chromatin, and plasma lipoproteins with very low density and forms aggregates with them. These aggregates also activate a complement cascade, which activity grows for each next step of the cascade, until the formation of a MAC. This is followed by phagocytosis, transport to Kupffer cells and spleen and, as a final result removal of foreign, damaged, and apoptotic cells. The maintenance of low-grade inflammation in an OA joint increases the metabolic activity of chondrocytes, including production of MMP, which, on their side, have a catabolic effect on the cartilage.

The major OA cells in the joint fluid are chondrocyte and synovicytes. Complement fractions bind to complement receptors on the surface of their cell membranes by TLR [50]. Sandeep Sila- wal asks the question whether the maintenance of balanced complement activation can represent a future therapeutic strategy of OA therapy and prevent its progression [51]. A team of Bulgarian immunologists have also contributed about that. In 2018, they published their observation on mice with collagen-induced monoarthritis as a model of activated OA. They prove a C5aR expression on mouse chondrocytes and $\mathrm{C} 5 \mathrm{aR}$ and $\mathrm{C} 3 \mathrm{aR}$ in the synoviocytes, as well as influence on the joint inflammation with them, through application of a C5aR antagonist [52].

The complement system is involved in many processes in the course of osteoarthritis: chondrocyte degeneration, ECM degradation, low-grade inflammation in the osteoarthritis, cell lysis, unbalanced bone remodeling, osteophyte formation, and reparative processes like neoangiogenesis. Science has not still solved the problem whether the complement cascade plays a role of the purification system only or is a leading pathogenic factor in OA activation.

Targeted studies regarding the participation of humoral and cellular factors of innate immunity would contribute for their therapeutic targeting as a future pathogenetic therapy of the disease.

\section{Библиография / References}

1. Scanzello CR, McKeon B, Swaim BH et al. Synovial inflammation in patients undergoing arthroscopic meniscectomy: molecular characterization and relationship to symptoms. Arthritis Rheum. 2011; 63:391-400.

2. Segal AW. Phagocytes. In Paediatric Immunology, Publ. Oxword, Melbourne, Toronto, 1983; 37-47

3. Бойкинов И. Имунитет и имунна недостатъчност, 2006, 21-31

4. Piccinini AM, Midwood KS. DAMPening inflammation by modulating TLR signalling. Mediators Inflamm. 2010;2010:672395. doi: 10.1155/2010/672395.13:45.

5. Ishijima M, Watari T, Naito K et al. Relationships between biomarkers of cartilage, bone, synovial metabolism and knee pain provide insights into the origins of pain in early knee osteoarthritis. Arthritis Res Ther. 2011;13:R22.

6. Janeway CA Jr. Medzhitov R. Innate immune recognition. Annu Rev Immunol. 2002; 20:197-216.

7. Carrion M, Juarranz Y, Perez-Garcia S et al. RNA sensors in human osteoarthritis and rheumatoid arthritis synovial fibroblasts: immune regulation by vasoactive intestinal peptide. Arthritis Rheum. 2011; 63:1626-36.

8. Kyburz D, Rethage J, Seibl R et al. Bacterial peptidoglycans but not $\mathrm{CpG}$ oligodeoxynucleotides activate synovial fibroblasts by toll-like receptor signaling. Arthritis Rheum. 2003; 48:642-50.

9. Ospelt C, Brentano F, Rengel Y et al. Overexpression of toll-like receptors 3 and 4 in synovial tissue from patients with early rheumatoid arthritis: toll-like receptor expression in early and longstanding arthritis. Arthritis Rheum. 2008; 58:3684-92. 
10. Ozawa T, Koyama K, Ando T et al. Thymic stromal lymphopoietin secretion of synovial fibroblasts is positively and negatively regulated by Toll-like receptors/nuclear factor-kappaB pathway and interferon-gamma/dexamethasone. Mod Rheumatol. 2007; 17:459-63.

11. Tamaki $Y$, Takakubo $Y$, Hirayama T et al. Expression of Tolllike receptors and their signaling pathways in rheumatoid synovitis. J Rheumatol. 2011; 38:810-20.

12. Akira S, Takeda K. Toll-like receptor signalling. Nat Rev Immunol. 2004; 4:499-511.

13. Marcu KB, Otero M, Olivotto E et al. NF-kappaB signaling: multiple angles to target OA. Curr Drug Targets. 2010; 11:599-613.

14. Sacks SH, Zhou W. The role of complement in the early immune response to transplantation. Nature Reviews Immunology. 2012;12:431-442.

15. Cem Gabay at al. S3. Interleukin-6 and chronic inflammation, Published online Arthritis Res Ther. 2006; 8 (Suppl 2). doi: 10.1186/ar1917

16. Colten HR. Biosynthesis of complement. Adv Immunol. 1976; 22: 67-118.

17. Abbas AK,LichmanAH,Pillai S. Kuy immunology. Macmillian, 2007. ISBN978-1-4292-0211-4.c.299; Cellular and Mollecular Immunology. 6th. Elsevier 2010. ISBN978-14160-3123-9.

18. Goldman AS, Prabhakar BS. The Complement System. in: Baron's Medical Microbiology (Baron S et al., eds.). 4th. Univ of Texas Medical Branch, 1996. ISBN 0-9631172-1-1.

19. Okumura N, Nomura M, Tada T. Effects of sample storage on serum c3c assay by nephelometry. Clin Labor Sci. 1990;3:54-57.

20. Garred P, Mollnes TE, Lea T. Quantification in enzyme-linked immunosorbent assay of a C3 neoepitope expressed on activated human complement factor C3. Scandinavian Journal of Immunology. 1988;27(3):329-335.

21. Greilling $\mathrm{H}$, at al. Chemie and Pathobiochemie, 3rd ed. 1995 : 1159-1162.

22. Muller-Eberhard HJ. Complement\& Chemistry and pathways. In inflammation \& Basic principles and clinical correlates. 1988; 21-53.

23. Shih AR, Murali MR. Laboratory tests for disorders of complement and complement regulatory proteins. First published: 06 October 2015.

24. Kishore U, Ghai R, Greenhough TJ, et al. Structural and functional anatomy of the globular domain of complement protein C1q. Immunol Lett 2004;95:113-128.

25. Merle NS, Church SE, Fremeaux-Bacchi V, Roumenina LT. Complement system. I. Molecular mechanisms of activation and regulation. Front Immunol 2015; 6:262.

26. Nilsson B, Nilsson Ekdahl K. The tick-over theory revisited: is C3 a contact-activated protein? Immunobiology 2012;217:1106-1110.

27. Mollnes TE, Jokiranta TS, Truedsson L, et al. Complement analysis in the 21st century. Mol Immunol 2007;44:38383849 .

28. Goldman AS, Prabhakar BS. The Complement System in Baron,s Medikal Microbiology 4th Univ of Texas Medical Branch,1996.

29. Abbas AK, Lichtman AH, Pillai S. Cellular and Molecular Immunology. 6th. Elsevier, 2010.

30. Ricklin D, Hajishengallis G, Yang K, Lambris JD. Complement: a key system for immune surveillance and homeostasis. Nat Immunol. 2010;11(9):785-97.
31. Happonen KE, Heinegård D, Saxne T, Blom AM. Interactions of the complement system with molecules of extracellular matrix: relevance for joint diseases. Immun, 2012;217(11):1088-96

32. Happonen KE, Saxne T, Aspberg A et al. Regulation of complement by cartilage oligomeric matrix protein allows for a novel molecular diagnostic principle in rheumatoid arthritis. Arthritis Rheum. 2010;62(12):3574-83.

33. Melin Fürst C, Mörgelin M, Vadstrup K et al. The C-type lectin of the aggrecan $\mathrm{G} 3$ domain activates complement. PLoS One. 2013;8(4):e61407.

34. Sjöberg A, Onnerfjord P, Mörgelin M et al. The extracellular matrix and inflammation: fibromodulin activates the classical pathway of complement by directly binding C1q. J Biol Chem. 2005;280(37):32301-8.

35. Okamura $Y$, Watari $M$, Jerud $E$ et al. The extra domain $A$ of fibronectin activates Toll-like receptor 4. J Biol Chem 2001, 276: 10229-10233

36. Termeer C, Benedix F, Sleeman J et al. Oligosaccharides of hyaluronan activate dendritic cells via toll-like receptor 4 . J Exp Med 2002,195: 99-111

37. Bondeson J, Blom AB, Wainwright $S$ et al. The role of synovial macrophages and macrophage-produced mediators in driving inflammatory and destructive responses in osteoarthritis. Arthritis Rheum. 2010; 62:647-57.

38. Sjoberg A, Onnerfjord P, Morgelin M et al. The extracellular matrix and inflammation: fibromodulin activates the classical pathway of complement by directly binding C1q. J Biol Chem. 2005; 280:32301-8.

39. Happonen KE, Saxne T, Aspberg A et al. Regulation of complement by cartilage oligomeric matrix protein allows for a novel molecular diagnostic principle in rheumatoid arthritis. Arthritis Rheum. 2010; 62:3574-83.

40. Swärd $P$, Frobell R, Englund $M$ et al. Cartilage and bone markers and inflammatory cytokines are increased in synovial fluid in the acute phase of knee injury (hemarthrosis) - a cross-sectional analysis. Osteoarthritis Cartilage. 2012;20(11):1302-8.

41. Struglics A, Okroj M, Swärd P, et al. The complement system is activated in synovial fluid from subjects with knee injury and from patients with osteoarthritisл Arthritis Res Therapy, 2016,18,223.

42. Sjoberg AP, Manderson GA, Morgelin M et al. Short leucine-rich glycoproteins of the extracellular matrix display diverse patterns of complement interaction and activation. Mol Immunol. 2009; 46:830-9.

43. Kalchishkova N, Furst CM, Heinegard D, Blom AM. NC4 Domain of Cartilage-specific Collagen IX Inhibits Complement Directly Due to Attenuation of Membrane Attack Formation and Indirectly through Binding and Enhancing Activity of Complement Inhibitors C4B-binding Protein and Factor H. J Biol Chem. 2011; 286:27915-26.

44. Mahla RS, Reddy MC, Prasad DV, Kumar H. Sweeten PAMPs: Role of Sugar Complexed PAMPs in Innate Immunity and Vaccine Biology .Front Immunol. 2013 Sep 2;4:248. doi: 10.3389/fimmu.2013.00248.

45. Takeda K, Akira SToll-like receptors in innate immunity.Int Immunol. 2005;17(1):1-14.

46. Nair A, Kanda V, Bush-Joseph C. et al. Synovial fluid from patients with early osteoarthritis modulates fibroblast-like synoviocyte responses to toll-like receptor 4 and toll-like recep- 
tor 2 ligands via soluble CD14. Arthritis Rheum., 2012;64(7): 2268-2277.

47. Sohn DH, Sokolove J, Sharpe O, et al. Plasma proteins present in osteoarthritic synovial fluid can stimulate cytokine production via Toll-like receptor 4. Arthritis Research and Therapy. 2012;14(1):R7. doi: 10.1186/ ar3555

48. Goldring MB, Otero M, Plumb DA et al. Roles of inflammatory and anabolic cytokines in cartilage metabolism: signals and multiple effectors converge upon MMP-13 regulation in osteoarthritis. Eur Cell Mater. 2011; 21:202-20.

49. Blom AB, Van Lent PL, Libregts $S$ et al. Crucial role of macrophages in matrix metalloproteinase-mediated cartilage

Постъпил за печат: 09.03.2021 2.

$\triangle$ Адрес за кореспонденция:

Д-р И. Момчева

Отделение по ревматология

УМБАЛ - Бургас destruction during experimental osteoarthritis: involvement of matrix metalloproteinase 3. Arthritis Rheum. 2007; 56:147-57.

50. King Strasinger S et al. Urinalysis and Body Fluids. Fifth Edition. 2008 F. A. Davis Co.

51. Silawal S, Triebel J, Bertsch T. First Published January 3 , 2018 Review Osteoarthritis and the Complement Cascad

52. Belenska-T L, Ganova P, Gyurkovska V, Ivanovska N. Complement System Involvement in Osteoarthritis Pathology Med Faculty, Publisher: MedDocs Publishers LLC, eBook: Osteoarthritis, Department of Immunology, Institute of Microbiology, Bulgaria

Submitted: 09.03.2021

$\triangle$ Correspondence address:

I. Momcheva, MD

Department of Rheumatology

UMHAT - Burgas 